Revta brasil. Bot., São Paulo, V.24, n.2, p.173-179, jun. 2001

\title{
Crescimento inicial de Euterpe edulis Mart. em diferentes regimes de luz
}

\author{
ERIKA MATSUNO NAKAZONO ${ }^{1}$, MARIA CLARA DA COSTA ${ }^{1}$, KAORI FUTATSUGI $^{1}$ e \\ MARIA TEREZINHA SILVEIRA PAULILO ${ }^{1,2}$
}

(recebido: 26 de junho de 2000; aceito: 7 de fevereiro de 2001)

\begin{abstract}
Early growth of Euterpe edulis Mart. in different light environments). Seedlings growing in deep shade (2 and $6 \%$ of full sun) showed, compared to seedlings growing at higher light levels, lower values of biomass, growth rates, root/shoot ratio, specific leaf weight (SLW), chlorophyll a/b ratio and higher value of leaf area ratio (LAR). With the increase in light availability, plants showed three different responses: 1) up to $20 \%$ of full sun, plants showed, with light increase, higher values of biomass, relative growth rate (RGR), unit leaf rate (ULR), root/shoot ratio, number of leaves, chlorophyll a/b ratio and lower values of leaf weight ratio (LWR) and LAR; 2 ) between $20 \%$ and $70 \%$ of full sun the seedlings did not show morphological or physiological alterations with increase in light, except higher chlorophyll a/b ratio at higher light levels; and 3) seedlings growing in full sun light showed lower biomass. Seedlings transferred from low to high light showed behavior similar to seedlings growing always in higher light. Stomatal density was slightly higher in plants transferred to higher light levels. Lower growth in deep shade and increase in growth with increasing light up to 20-30\% of sun light may indicate that the regeneration of this species can take advantage of the appearance of a clearing. The lower performance in full sun and in deep shade may indicate limited competitive capacity of the species in large clearings and in very closed canopies.
\end{abstract}

RESUMO - (Crescimento inicial de Euterpe edulis Mart. em diferentes regimes de luz). Plantas sob forte sombreamento (2\% ou 6\% da luz solar direta) apresentaram, em relação às plantas sob maior nível de luz, menor biomassa, menores taxas de crescimento, menor razão raiz/parte aérea, menor massa foliar específica (MFE), menor razão clorofila a/b e maior razão de área foliar (RAF). Com o aumento da irradiância as plantas apresentaram três tipos de comportamento, dependendo da quantidade de luz dada: 1) até cerca de $20 \%$ da luz solar direta as plantas apresentaram, com aumento da luz, aumento de biomassa, das taxas de crescimento relativo (TCR) e de assimilação líquida (TAL), maior alocação de biomassa para a raiz, maior número de folhas, maior MFE, maior razão clorofila a/b e menor razão de peso foliar (RPF) e RAF; 2) entre $20 \%$ e $70 \%$ de luz as plantas não mostraram alterações morfológicas ou fisiológicas com aumento na quantidade de luz, à exceção de um aumento na razão clorofila a/b; e 3) plantas crescendo em luz solar plena apresentaram uma redução do crescimento em massa seca. As plantas transferidas de $4 \%$ para 20 ou $30 \%$ de luz mostraram respostas similares àquelas das plantas crescidas sempre em mais luz. A densidade de estômatos mostrou uma leve tendência ao aumento em plantas transferidas para maior quantidade de luz. O menor crescimento em níveis mais fortes de sombreamento e o maior crescimento com aumento de irradiância até $20-30 \%$ da luz solar total sugere que a espécie possa se beneficiar do aparecimento de clareiras para sua regeneração. $\mathrm{O}$ menor desempenho das plantas em condições de luz plena ou forte sombreamento sugere menor capacidade competitiva da espécie em grandes clareiras ou sob dossel fechado.

Key words - light acclimation, Euterpe edulis, growth

\section{Introdução}

A estrutura das florestas tropicais permite que pequena quantidade de luz chegue ao nível do chão da floresta (Chazdon \& Fetcher 1984, Januário et al. 1992). Como consequiência, o crescimento de muitas plântulas nestas florestas pode ser limitado pela quantidade de luz disponível e muitas desenvolvem estratégias para sobreviverem e se estabelecerem neste ambiente de pouca luz (Osunkoya et al. 1994, Claussen 1996). Por outro lado, plântulas crescendo no interior de uma floresta tropical passam por

1. Universidade Federal de Santa Catarina, Centro de Ciências Biológicas, Departamento de Botânica, 88040-900 Florianópolis, SC, Brasil.

2. Autor para correspondência: paulilo@ccb.ufsc.br mudanças bruscas na quantidade de luz, estando sujeitas a incidências de luz que variam com as horas do dia, com as estações do ano, com a movimentação de copas, ou devido à queda de outros vegetais ao redor (Osunkoya \& Ash 1991, Lee et al. 1997).

As espécies arbóreas variam grandemente na sua capacidade de responder à alteração na disponibilidade de luz (Thompson et al. 1992). As respostas apresentadas pelas plantas à variação na disponibilidade de luz costumam envolver alterações nas características das folhas relacionadas à fotossíntese, como a razão clorofila a/b, espessura foliar, teor de nitrogênio, densidade estomática, e/ou alterações na proporção de tecidos fotossintetizantes em relação aos não fotossintetizantes, levando à modificação na distribuição de biomassa (Popma \& Bongers 1991, Osunkoya et al. 1994). 
Muitos dos estudos do comportamento de espécies arbóreas tropicais em relação à variação de luz têm sido feitos crescendo as plântulas em diferentes quantidades de luz constante, entretanto, na natureza uma mesma plântula experimenta variações na quantidade de luz, devido à abertura ou ao fechamento de clareiras e a resposta da planta ao novo ambiente pode ser afetada pelo ambiente prévio ao qual ela estava submetida (Oberbauer \& Strain 1985, Kitajima 1996).

O conhecimento sobre os requerimentos de luz para espécies arbóreas tropicais é importante tanto para a recomposição de florestas como para o desenvolvimento de plantações de espécies economicamente importantes. O objetivo deste trabalho foi verificar em Euterpe edulis Mart., espécie do estrato médio da Floresta Ombrófila Densa da Encosta Atlântica (Reis et al. 1996), tida como de sombra (Klein 1980), cuja regeneração natural tem sido comprometida devido à intensa ação extrativista (Reis et al. 1991), os seguintes aspectos: a) o crescimento de plântulas seria limitado pela quantidade de luz que chega ao nível do chão da floresta? b) ocorreriam alterações morfo-fisiológicas nas plântulas com a variação na quantidade de luz? c) a resposta de plântulas crescidas em diferentes quantidades de luz constante, ou transferidas de baixa para alta quantidade de luz seria similar? Sendo assim, as plântulas seriam capazes de responder ao aumento na quantidade de luz resultante, por exemplo, do aparecimento de uma clareira?

\section{Material e métodos}

Obtenção das plantas - Frutos de Euterpe edulis Mart. foram coletados em seis diferentes árvores localizadas na região de Mata Atlântica do Estado de Santa Catarina e estocadas a $5{ }^{\circ} \mathrm{C}$ até o início dos experimentos. Os frutos foram despolpados através de fricção manual e os conjuntos endocarpo mais semente resultantes foram colocados para germinar, em casa de vegetação, em caixas de madeira contendo areia lavada.

Crescimento de plantas - Foram feitos três experimentos, onde plântulas de $E$. edulis com cerca de 2,5 cm de epicótilo, provindas da germinação de sementes, foram colocadas em sacos plásticos de $20 \times 7 \mathrm{~cm}$, contendo substrato composto por argila, adubo orgânico e areia na proporção de 2:2:1. Os sacos plásticos, contendo uma planta cada, foram colocados sob caixas de $1 \mathrm{~m}^{3}$, confeccionadas com tela sombrite, que permitiam a passagem de diferentes níveis de luz. O experimento 1 ocorreu no período de agosto a janeiro, o experimento 2, de outubro a janeiro e o experimento 3, de novembro a fevereiro.

Experimento 1 - Plantas de E. edulis foram colocadas sob caixas de tela sombrite que permitiam aos diferentes lotes de plantas receberem $70 \%, 50 \%, 30 \%$ e $20 \%$ da luz solar direta. Um lote de plantas ficou sob luz solar direta. Foram feitas coletas de plantas para análise aos 89, 117, 159 e 199 dias após o início dos tratamentos, à exceção das plantas em luz solar direta, que foram analisadas apenas aos 199 dias de tratamento.

Experimento 2 - Plantas de E. edulis foram colocadas sob caixas de tela sombrite, recebendo os diferentes lotes de plantas, $2 \%, 6 \%$ e $20 \%$ da luz solar direta. Foram feitas coletas de plantas para análise aos 86 e 135 dias após o início dos tratamentos.

Experimento 3 - Plantas de E. edulis foram colocadas sob caixas de tela sombrite permitindo a passagem de $4 \%$ da luz solar direta. As plantas permaneceram nesta condição por 107 dias e, então, foram divididas em três lotes: o primeiro lote permaneceu em $4 \%$ da luz solar direta, o segundo, foi transferido para caixas permitindo a passagem de $20 \%$ da luz solar direta, e o terceiro foi transferido para caixas permitindo a passagem de $30 \%$ da luz solar direta. Foram feitas coletas de plantas aos 48 e 110 dias após a transferência das plantas.

Os níveis de luz foram determinados medindo-se com um quantômetro LICOR-250 a densidade de fluxo de fótons a pleno sol e sob as telas sombrite, calculando-se, então, a porcentagem de passagem de luz sob as telas sombrite. A densidade de fluxo de fótons medida a pleno sol, ao meio dia, em dia claro próximo ao solstício de verão foi cerca de $1800 \mu \mathrm{mol}$ de fótons $\mathrm{m}^{-2} . \mathrm{s}^{-1}$.

Determinação de massa seca e área foliar - A massa seca foi obtida colocando-se as plantas, separadas em raiz, caule (conjunto formado pelo caule mais bainhas e pecíolos foliares) e lâminas foliares, em estufa a $80{ }^{\circ} \mathrm{C}$ por 48 horas. Após este período, as diferentes partes das plantas foram pesadas separadamente em balança analítica. A área foliar foi calculada comparando-se o contorno de lâminas foliares desenhadas em papel com peso de áreas conhecidas do mesmo papel.

Análise de crescimento - A taxa média de crescimento relativo (TCR), foi calculada pela equação (ln $\left.\mathrm{M}_{2}-\ln \mathrm{M}_{1}\right) /\left(\mathrm{T}_{2}-\mathrm{T}_{1}\right)$; a taxa média de assimilação líquida (TAL), pela equação $\left[\left(\mathrm{M}_{2}-\mathrm{M}_{1}\right) /\left(\mathrm{T}_{2}\right.\right.$ - $\left.\left.T_{1}\right)\right]$ x [(ln $\left.\left.A_{2}-\ln A_{1}\right) /\left(A_{2}-A_{1}\right)\right]$; a razão média da área foliar (RAF), pela equação $\left(\mathrm{A}_{1} / \mathrm{M}_{1}\right)+\left(\mathrm{A}_{2} / \mathrm{M}_{2}\right) / 2$; a massa foliar específica (MFE), que é o inverso da área foliar específica e dá uma estimativa da espessura foliar (Hunt 1982), pela equação $\mathrm{M}_{\mathrm{lf}} / \mathrm{A}$; e a razão de massa foliar (RMF) pela equação $\mathrm{M}_{\mathrm{lf}} / \mathrm{M}$ onde: $\mathrm{M}$ representa o massa seca total, $M_{\text {lf }}$ representa massa seca da lâmina foliar, T representa o tempo e A representa a área foliar (Hunt 1982). Determinação do teor de clorofila - Discos de folhas frescas de três diferentes plantas por tratamento, somando $50 \mathrm{mg}$ por planta, foram incubados em dimetil-sulfóxido por 10 horas a $65^{\circ} \mathrm{C}$ para a extração completa da clorofila (Hiscox \& Israelstam 1979). A absorbância da solução de clorofila resultante, medida em espectrofotômetro a $663 \mathrm{~nm}$ para a clorofila a e a $645 \mathrm{~nm}$ para a clorofila $b$, foi utilizada para o cálculo do teor de clorofila, segundo Arnon (1949).

Determinação da densidade de estômatos - Uma réplica das superfícies superior e inferior da folha foi tirada com esmalte incolor para unhas. A contagem de estômatos foi feita nesta réplica com auxílio de microscópio óptico munido com câmara clara. Foram contados estômatos em 6 a 7 campos de $100 \mathrm{x}$ $200 \mu \mathrm{m}^{2}$, entre nervuras, em três diferentes plantas por 
tratamento, totalizando 20 campos por planta. Foram utilizadas porções medianas de pinas da mais nova folha com expansão completa.

Determinação da espessura foliar - Foram feitas lâminas permanentes com secções transversais de porções medianas de pinas segundo método de desidratação em etanol, passagem em xilol e inclusão em parafina (Johansen 1940). As medidas de espessura da epiderme e mesofilo das secções transversais das pinas foram feitas com auxílio de microscópio óptico e disco micrométrico acoplado à ocular. Foram utilizadas três plantas por tratamento, sendo que de cada planta foram tomadas medidas de cinco cortes e de cada corte cinco medidas em locais distintos.

Número de amostras e análise estatística - Nos três experimentos feitos foram analisadas nove plantas por tratamento, a não ser quando especificado de maneira diferente. Para comparação de mais de duas médias foi utilizada análise de variância seguida de teste Tukey. Para comparação de duas médias foi utilizado teste T de Student (Snedecor 1962).

\section{Resultados}

Biomassa, área foliar e número de folhas - Em plantas crescidas sempre sob a mesma quantidade de luz, observou-se que aquelas crescidas em $20 \%$, $30 \%, 50 \%$ e $70 \%$ de luz tiveram crescimento semelhante em termos de massa seca, área foliar e distribuição de biomassa entre raiz e parte aérea, mas diferiram das plantas crescidas em luz solar direta, apresentando estas últimas crescimento menor em massa seca que aquelas sombreadas (tabela 1). Já em plantas crescidas a $2 \%, 6 \%$ e $20 \%$ de luz, a massa seca de raiz e parte aérea, a área foliar, o número de folhas e a distribuição de biomassa para a raiz tenderam a ser maiores quanto maior o nível de luz em que as plantas cresceram (tabela 1). Plantas transferidas de baixa (4\%) para alta (20\% ou $30 \%)$ quantidade de luz responderam ao aumento na irradiância, aumentando a massa seca de raiz e parte aérea, a área foliar, o número de folhas e a distribuição de biomassa para a raiz (tabela 1).

Taxas de crescimento - Plantas crescidas em 20\%, $30 \%, 50 \%$ e $70 \%$ de luz não diferiram com relação a TCR, TAL, RAF, MFE e RMF (tabela 2). Em plantas crescidas a $2 \%, 6 \%$ e $20 \%$ de luz, a TCR, a TAL e a MFE foram maiores a $20 \%$ que a $2 \%$ de luz. A RAF e RMF foram significativamente menores em maior nível de luz (tabela 2). As plantas transferidas de $4 \%$ de luz para $20 \%$ ou $30 \%$ de luz mostraram maiores TCR e TAL que aquelas que permaneceram a $4 \%$ de luz, enquanto a RAF foi semelhante em plantas transferidas e não transferidas (tabela 2). A MFE foi maior e a RMF foi menor em plantas transferidas para $30 \%$ de luz (tabela 2).

Clorofila, espessura da folha e densidade de estômatos - Nas quantidades de luz testadas, tanto em plantas sempre sob o mesmo sombreamento como naquelas transferidas para mais luz, os teores de clorofila a e b tenderam a ser menores quanto maior a quantidade de luz, enquanto a razão entre clorofila a/b tendeu a ser maior (tabela 3). A

Tabela 1. Massa seca de órgãos, área foliar, razão raiz/parte aérea (R/PA) e número de folhas de plantas de Euterpe edulis crescidas sob diferentes níveis de luz. Médias seguidas da mesma letra na vertical não diferem estatisticamente entre si pelo teste de Tukey em $5 \%$ de probabilidade. Letras comparam dentro de um mesmo experimento. (4\%-20\% ) - (4\%-30\%) - Plantas crescidas em 4\% de luz e posteriormente transferidas para $20 \%$ ou 30\% de luz. Exp. 1 - plantas com 199 dias de tratamento; Exp. 2 - plantas com 135 dias de tratamento; Exp. 3 - plantas com 110 dias de tratamento.

\begin{tabular}{|c|c|c|c|c|c|c|c|}
\hline & Nível de luz & Raiz (mg) & Parte aérea $(\mathrm{mg})$ & Total (mg) & Área foliar $\left(\mathrm{cm}^{2}\right)$ & $\mathrm{R} / \mathrm{PA}$ & Folhas $\left(\mathrm{n}^{\circ}\right)$ \\
\hline \multirow{5}{*}{ Exp. 1} & $100 \%$ & $232,00 \mathrm{a}$ & $523,10 \mathrm{a}$ & $754,10 \mathrm{a}$ & $79,00 \mathrm{a}$ & $0,44 \mathrm{a}$ & - \\
\hline & $70 \%$ & $306,20 \mathrm{a}$ & $1006,90 \mathrm{a}$ & $1313,10 \mathrm{a}$ & $160,60 \mathrm{~b}$ & $0,30 \mathrm{~b}$ & - \\
\hline & $50 \%$ & $301,30 \mathrm{a}$ & $895,50 \mathrm{a}$ & $1196,80 \mathrm{a}$ & $144,20 \mathrm{~b}$ & $0,34 b$ & - \\
\hline & $30 \%$ & $271,70 \mathrm{a}$ & $938,80 \mathrm{a}$ & $1210,50 \mathrm{a}$ & $174,60 \mathrm{~b}$ & $0,29 b$ & - \\
\hline & $20 \%$ & $272,70 \mathrm{a}$ & $1038,70 \mathrm{a}$ & $1311,40 \mathrm{a}$ & $202,80 \mathrm{~b}$ & $0,26 b$ & - \\
\hline \multirow{3}{*}{ Exp. 2} & $20 \%$ & $395,00 \mathrm{a}$ & $662,00 \mathrm{a}$ & $1057,00 \mathrm{a}$ & $124,42 \mathrm{a}$ & $0,59 \mathrm{a}$ & $2,3 \mathrm{a}$ \\
\hline & $6 \%$ & $211,00 \mathrm{~b}$ & $524,00 \mathrm{~b}$ & $735,00 \mathrm{~b}$ & $111,24 \mathrm{ab}$ & $0,42 b$ & $2,0 \mathrm{a}$ \\
\hline & $2 \%$ & $132,00 \mathrm{~b}$ & $304,00 \mathrm{c}$ & $436,00 \mathrm{c}$ & $79,05 b$ & $0,44 \mathrm{~b}$ & $1,3 b$ \\
\hline \multirow{3}{*}{ Exp. 3} & $4 \%-30 \%$ & $497,00 \mathrm{a}$ & $1169,22 \mathrm{a}$ & $1666,22 \mathrm{a}$ & $157,41 \mathrm{a}$ & $0,42 \mathrm{a}$ & $3,0 \mathrm{a}$ \\
\hline & $4 \%-20 \%$ & $403,44 a$ & $910,56 \mathrm{~b}$ & $1314,00 \mathrm{~b}$ & $139,24 b$ & $0,44 \mathrm{a}$ & $3,0 \mathrm{a}$ \\
\hline & $4 \%$ & $173,56 \mathrm{~b}$ & $562,11 \mathrm{c}$ & $735,67 \mathrm{c}$ & $98,97 \mathrm{~b}$ & $0,32 \mathrm{~b}$ & $2,0 \mathrm{~b}$ \\
\hline
\end{tabular}


Tabela 2. Taxa de crescimento relativo (TCR), taxa de assimilação líquida (TAL), razão de área foliar (RAF), razão de peso foliar (RPF) e massa foliar específica (MFE) de plantas de Euterpe edulis crescidas sob diferentes níveis de luz. Médias seguidas da mesma letra na vertical não diferem estatisticamente entre si pelo teste de Tukey em 5\% de probabilidade. Letras comparam dentro de um mesmo experimento. (4\%-20\% ) - (4\%-30\%) - Plantas crescidas em 4\% de luz e posteriormente transferidas para $20 \%$ ou $30 \%$ de luz. Exp. 1 - taxas calculadas entre 89 e 199 dias de tratamento; Exp. 2 - taxas calculadas entre 86 e 135 dias de tratamento; Exp. 3 - taxas calculadas entre 48 e 110 dias de tratamento. RPF e MFE calculadas na última coleta.

\begin{tabular}{|c|c|c|c|c|c|c|}
\hline & Nível de luz & TCR $\left(m g \cdot \mathrm{mg}^{-1} \cdot \mathrm{d}^{-1}\right)$ & TAL $\left(\mathrm{mg} \cdot \mathrm{cm}^{-2} \cdot \mathrm{d}^{-1}\right)$ & $\operatorname{RAF}\left(\mathrm{cm}^{2} \cdot \mathrm{mg}^{-1}\right)$ & $\mathrm{RPF}\left(\mathrm{mg} \cdot \mathrm{mg}^{-1}\right)$ & $\operatorname{MFE}\left(\mathrm{mg} \cdot \mathrm{cm}^{-2}\right)$ \\
\hline \multirow{4}{*}{ Exp.1 } & $70 \%$ & $0,017 \mathrm{a}$ & $0,16 \mathrm{a}$ & $0,11 \mathrm{a}$ & $0,46 \mathrm{a}$ & $4,50 \mathrm{a}$ \\
\hline & $50 \%$ & $0,017 \mathrm{a}$ & $0,14 \mathrm{a}$ & $0,12 \mathrm{a}$ & $0,45 \mathrm{a}$ & $4,50 \mathrm{a}$ \\
\hline & $30 \%$ & $0,017 \mathrm{a}$ & $0,15 \mathrm{a}$ & $0,12 \mathrm{a}$ & $0,46 \mathrm{a}$ & $4,20 \mathrm{a}$ \\
\hline & $20 \%$ & $0,018 \mathrm{a}$ & $0,15 \mathrm{a}$ & $0,11 \mathrm{a}$ & $0,47 \mathrm{a}$ & $4,20 \mathrm{a}$ \\
\hline \multirow{3}{*}{ Exp.2 } & $20 \%$ & $0,012 \mathrm{a}$ & $0,11 \mathrm{a}$ & $0,12 \mathrm{a}$ & $0,39 a$ & $3,30 \mathrm{a}$ \\
\hline & $6 \%$ & $0,009 b$ & $0,06 \mathrm{~b}$ & $0,15 b$ & $0,45 b$ & $2,90 \mathrm{ab}$ \\
\hline & $2 \%$ & $0,005 \mathrm{c}$ & $0,03 \mathrm{c}$ & $0,17 \mathrm{~b}$ & $0,45 b$ & $2,50 \mathrm{~b}$ \\
\hline \multirow{3}{*}{ Exp.3 } & $4 \%-30 \%$ & $0,018 \mathrm{a}$ & $0,12 \mathrm{a}$ & $0,15 \mathrm{a}$ & $0,43 \mathrm{a}$ & $4,60 \mathrm{a}$ \\
\hline & $4 \%-20 \%$ & $0,014 \mathrm{a}$ & $0,11 \mathrm{a}$ & $0,13 \mathrm{a}$ & $0,42 \mathrm{a}$ & $3,90 \mathrm{ab}$ \\
\hline & $4 \%$ & $0,008 \mathrm{~b}$ & $0,06 \mathrm{~b}$ & $0,11 \mathrm{a}$ & $0,47 \mathrm{~b}$ & $3,50 \mathrm{~b}$ \\
\hline
\end{tabular}

Tabela 3. Teores de clorofila a, clorofila b e razão clorofila a/b $(\mathrm{Cl}$ a/Cl b) em plantas Euterpe edulis, crescidas sob diferentes níveis de luz. Médias seguidas da mesma letra na vertical não diferem estatisticamente entre si pelo teste de Tukey em 5\% de probabilidade. Letras comparam dentro de um mesmo experimento. (4\%-20\%) - (4\%-30\%) - Plantas crescidas em 4\% de luz e posteriormente transferidas para $20 \%$ ou $30 \%$ de luz. Exp. 1 - plantas com 199 dias de tratamento; Exp. 2 - plantas com 135 dias de tratamento; Exp. 3 - plantas com 110 dias de tratamento. Clorofila determinada em massa fresca.

\begin{tabular}{lcccc}
\hline & Nível de luz & Clorofila a $\left(\mu \mathrm{g}_{\mathrm{mg}}{ }^{-1}\right)$ & Clorofila b $\left(\mu \mathrm{g}_{\mathrm{mg}}{ }^{-1}\right)$ & $\mathrm{Cl} \mathrm{a} / \mathrm{Cl} \mathrm{b}$ \\
\hline & $70 \%$ & $0,82 \mathrm{a}$ & $0,87 \mathrm{a}$ & $0,94 \mathrm{a}$ \\
Exp. 1 & $50 \%$ & $1,00 \mathrm{~b}$ & $1,13 \mathrm{~b}$ & $0,89 \mathrm{~b}$ \\
& $30 \%$ & $1,25 \mathrm{c}$ & $1,49 \mathrm{c}$ & $0,84 \mathrm{c}$ \\
& $20 \%$ & $1,25 \mathrm{c}$ & $1,52 \mathrm{c}$ & $0,82 \mathrm{c}$ \\
\hline \multirow{2}{*}{ Exp. 2} & $20 \%$ & $1,49 \mathrm{a}$ & $2,21 \mathrm{a}$ & $0,67 \mathrm{a}$ \\
& $6 \%$ & $1,79 \mathrm{~b}$ & $2,81 \mathrm{~b}$ & $0,63 \mathrm{~b}$ \\
& $2 \%$ & $1,88 \mathrm{~b}$ & $3,02 \mathrm{~b}$ & $0,62 \mathrm{~b}$ \\
\hline
\end{tabular}

espessura do mesofilo foliar foi maior, a espessura das epidermes não variou e a densidade estomática mostrou leve tendência ao aumento em plantas transferidas para mais alto nível de luz (tabela 4).

\section{Discussão}

Plantas recebendo $2 \%$ ou $6 \%$ da luz solar direta apresentaram menor biomassa e menores taxas de crescimento que plantas crescidas a $20 \%$ da luz solar direta. Estes resultados indicam que a quantidade de luz presente ao nível do chão de florestas tropicais, entre $0,5 \%$ e $4 \%$ da luz solar direta (Chazdon \& Fetcher 1984, Januário et al. 1992) é limitante para o crescimento de plantas de Euterpe edulis. A presença de fachos temporários de luz (sunflecks), existentes quando a luz solar direta passa através de aberturas no dossel, pode minimizar esta escassez de 
Tabela 4. Espessura do mesofilo foliar, altura das epidermes e densidade estomática de plantas de Euterpe edulis crescidas sob diferentes níveis de luz. Médias seguidas da mesma letra na vertical não diferem estatisticamente entre si pelo teste de Tukey ou Student em 5\% de probabilidade. Letras comparam dentro de um mesmo experimento. (4\%-20\% ) - (4\%-30\%) - Plantas crescidas em $4 \%$ de luz e posteriormente transferidas para $20 \%$ ou $30 \%$ de luz. Experimento 3 - plantas com 110 dias de tratamento. Epiderme superior (ES), epiderme inferior (EI).

\begin{tabular}{lcccc}
\hline $\begin{array}{l}\text { Nível de } \\
\text { luz }\end{array}$ & $\begin{array}{c}\text { Espessura do } \\
\text { mesofilo } \\
(\mu \mathrm{m})\end{array}$ & $\begin{array}{c}\text { Altura das } \\
\text { epidermes } \\
(\mu \mathrm{m})\end{array}$ & \multicolumn{2}{c}{$\begin{array}{c}\text { Densidade estomática } \\
\left(\mathrm{n}^{\circ} \cdot \mathrm{mm}^{-2}\right)\end{array}$} \\
\hline $4 \%-30 \%$ & $54,69 \mathrm{a}$ & $12,63 \mathrm{a}$ & $20 \mathrm{a}$ & $280 \mathrm{a}$ \\
$4 \%-20 \%$ & - & - & $10 \mathrm{a}$ & $250 \mathrm{a}$ \\
$4 \%$ & $44,55 \mathrm{~b}$ & $12,00 \mathrm{~b}$ & $20 \mathrm{a}$ & $245 \mathrm{a}$ \\
\hline
\end{tabular}

luz ao nível das plântulas e contribuir para um aumento temporário da taxa fotossintética (Valladares et al. 1997). As plantas sob forte sombreamento apresentaram alterações que levam a maximizar a captura de luz, como aumento na proporção de clorofila $b$ em relação à clorofila $a$ (Critchley 1999), aumento da razão de área foliar, diminuição da razão entre raiz e parte aérea e diminuição na massa foliar específica (Dias-Filho 1997, Reich et al. 1998). As alterações morfológicas, entretanto, nem sempre garantem aumento de matéria seca (Oberbauer \& Strain 1985) e as alterações morfológicas ocorridas em E. edulis não impediram uma redução nas taxas de assimilação líquida e de crescimento, levando a uma redução em massa seca, resposta que costuma ocorrer em plantas que não se adaptam ao novo ambiente a que estão sendo submetidas (Holmes \& Cowling 1993).

Com relação ao aumento na quantidade de luz, dependendo da quantidade aplicada, as plantas mostraram três tipos de comportamento: 1) aumento de crescimento, 2) ausência de resposta e 3) diminuição do crescimento:

1) Aumento de crescimento - até cerca de $20 \%$ da luz solar direta as plantas apresentaram alterações morfológicas e fisiológicas com aumento da luz típicas de plantas crescendo em maior quantidade de luz (Popma \& Bongers 1991, Reich et al. 1998), como aumento de biomassa, das taxas de crescimento e de assimilação líquida, maior alocação de biomassa para a raiz, maior número de folhas, maior massa foliar específica, maior razão clorofila a/b e menor razão de massa foliar e de área foliar. Alteração da TCR é dependente de alteração na fisiologia, medida pela TAL, e/ou na morfologia da planta, medida pela RAF (Hunt 1982). No caso de E. edulis, o aumento da TCR em mais luz foi resultado de alterações fisiológicas que levaram ao aumento da TAL. A RAF, ao contrário, foi menor em plantas crescendo em mais luz, não contribuindo para o incremento da TCR nestas plantas. A RAF assumiu maior importância para a elevação da TCR em plantas crescendo em menos luz, já que neste caso a TAL foi bastante reduzida. Claussen (1996) discute as implicações ecológicas de algumas dessas alterações: a mais alta razão raiz/parte aérea e menor razão de massa foliar em plantas de ambientes mais iluminados indicam que a biomassa foi distribuída mais para raízes que para órgãos fotossintetizantes, permitindo maior absorção de água e nutrientes, estratégia esta que garantiria maior capacidade para suportar as maiores taxas de fotossíntese e transpiração que ocorrem nestes ambientes; uma baixa razão de área foliar seria benéfica uma vez que menos material vegetal é exposto a eventuais danos por excesso de luz; uma alta massa foliar específica (folhas mais grossas) seria benéfica porque menos material vegetal por unidade de área seria diretamente exposto à luz, reduzindo a perda de água e aumentando o auto-sombreamento entre cloroplastos. A diminuição da quantidade de clorofila b em relação à clorofila a estaria relacionada à menor proporção de fotossistema II, que é mais rico em clorofila b que a, em relação ao Fotossistema I (Anderson et al. 1988, Critchley 1999). As plantas transferidas de $4 \%$ para 20 ou $30 \%$ de luz mostraram respostas similares àquelas das plantas crescidas sempre em mais luz, indicando que o ambiente prévio ao qual as plantas estavam submetidas não alterou o tipo de resposta à variação de luz. A densidade de estômatos mostrou uma leve tendência ao aumento em plantas transferidas para maior quantidade de luz. O aumento da densidade de estômatos com aumento de irradiância é uma resposta encontrada em plântulas de muitas espécies (Holmes \& Cowling 1993), entretanto, E. edulis mostrou baixa plasticidade em relação a este parâmetro.

2) Ausência de resposta - entre $20 \%$ e $70 \%$ de luz as plantas não mostraram alterações morfológicas ou 
fisiológicas com aumento na quantidade de luz, à exceção de um aumento na razão clorofila a/b. Estes resultados mostram que plantas de E. edulis têm uma capacidade limitada de responderem ao aumento de irradiância. Há evidências experimentais de muitas outras espécies que mostram aumento do crescimento em irradiâncias logo acima de forte sombreamento, mas nenhum ou pequeno crescimento quando o nível de luz excede a 20 ou $30 \%$ da luz solar plena (Osborne et al. 1994, Poorter 1999, Valladares et al. 2000). A posição sucessional das espécies tem sido utilizada por alguns autores para explicar a maior ou menor plasticidade das plantas em responder à variação de luz, com espécies de estágios sucessionais mais tardios tendo menor plasticidade que espécies de estágios sucessionais mais iniciais (Huante \& Rincón 1998). Assim, poder-se-ia atribuir a falta de plasticidade de $E$. edulis em adaptar-se a esta faixa de luz à sua posição sucessional de espécie não pioneira (Klein 1980), embora não haja consenso sobre a relação entre posição successional das espécies e plasticidade na adaptação à variação de luz (Turnbull 1991, Strauss-Debenedetti \& Bazzaz 1996).

3) Diminuição do crescimento - plantas de E. edulis crescendo em luz solar plena apresentaram uma redução do crescimento em massa seca, mostrando-se intolerantes a esta quantidade de luz. Estes resultados estão de acordo com os dados de literatura sobre E. edulis, que mostram necessitar a espécie de um certo grau de sombreamento durante seu crescimento inicial (Yamazoe 1973, Mattos \& Mattos 1976, Reis et al. 1987, Bovi et al. 1990). O comportamento apresentado por E. edulis é encontrado em outras espécies onde a exposição prolongada a altas irradiâncias pode ser prejudicial às plântulas que absorvem mais fótons de luz do que podem utilizar, levando à fotoinibição da fotossíntese ou mesmo à morte devido ao dano causado ao aparelho fotossintético pela quantidade excedente de fótons de luz (Sonoike 1996, Kitao et al. 2000).

Os resultados encontrados para E. edulis em relação à variação na quantidade de luz mostram que as plantas diferem na sua resposta à variação de luz, dependendo do nível de luz a que estão submetidas. O menor crescimento em níveis mais fortes de sombreamento e a aclimatação ao aumento de irradiância até 20 - 30\% da luz solar total, quantidade de luz similar a que chega a uma clareira de tamanho médio - $400 \mathrm{~m}^{2}$ (Oberbauer \& Strain 1985), sugere que a espécie possa se beneficiar do aparecimento de clareiras para sua regeneração. O menor desempenho das plantas em condições de plena luz ou forte sombreamento pode limitar a capacidade competitiva da espécie em grandes clareiras ou sob dossel fechado (Oberbauer \& Strain 1985, Chazdon 1992). Embora E. edulis não tenha mostrado se adaptar ao aumento da quantidade de luz acima de 20-30\% da luz solar plena, isto não significa que a espécie não possa explorar ambientes com altas irradiâncias, como já verificado para Mycelis muralis (Osborne et al. 1994) e Platycyamus regnellii (Scalon \& Alvarenga 1993), que se mostraram capazes de crescer em irradiâncias bastante altas sem apresentarem alterações morfológicas ou fisiológicas.

Agradecimentos - Erika M. Nakazono, M. Clara da Costa e Kaori Futatsugi agradecem ao CNPq pela bolsa concedida. As autoras agradecem a Ana Lúcia Scheffer e João de Deus Medeiros pelo auxílio nas técnicas anatômicas.

\section{Referências bibliográficas}

ANDERSON, J.M., CHOW, W.S. \& GOODCHILD, D.J. 1988. Thylakoid membrane organization in sun/shade acclimation. Australian Journal of Plant Physiology 15:11-26.

ARNON, D.J. 1949. Copper enzime in isolated chloroplast. Polyphenoloxidase in Beta vulgaris. Plant Physiology 24:1-15.

BOVI, M.L.A., GODOY JR, G., NAGAI, V. \& CARDOSO, M. 1990. Densidade de plantio de palmiteiro em consórcio com seringueiras. Pesquisa Agropecuária Brasileira 25:1023-1029.

CHAZDON, R.L. 1992. Photosynthetic plasticity of two rain forest shrubs across natural gap transects. Oecologia 92:586-595.

CHAZDON, R.L. \& FETCHER, N. 1984. Photosynthetic light environment in a lowland tropical rain forest in Costa Rica. Journal of Ecology 72:553-564.

CLAUSSEN, J.W. 1996. Acclimation abilities of three tropical rainforest seedlings to an increase in light intensity. Forest Ecology and Management 80:245-255.

CRITCHLEY, C. 1999. Molecular adaptation to irradiance: The dual functionality of photosystem II. In Concepts in photobiology: Photosynthesis and photomorphogenesis (G.S. Singhal, G. Renger, S.K. Sopory, K-D. Irrgang \& Govindjee, eds.). Narosa Publishing House, New Delhi, p.573-587. 
DIAS-FILHO, M.B. 1997. Physiologycal response of Solanum crinitum Lam. to contrasting light environments. Pesquisa Agropececuária Brasileira 32:789-796.

HISCOX, J.D. \& ISRAESLTAM, G.F. 1979. A method for extration of chlorophyll from leaf without maceration. Canadian Journal of Botany 57:1332-1334.

HOLMES, P.M. \& COWLING, R.M. 1993. Effects of shade on seedlings growth, morphology and leaf photosynthesis in six subtropical thicket species from eastern Cape, South Africa. Forest Ecology Management 61:199-220.

HUANTE, P. \& RINCÓN, E. 1998. Responses to light changes in tropical deciduous woody seedlings with contrasting growth rates. Oecologia 113:53-56.

HUNT, R. 1982. Plant growth curves: The functional approach to plant growth analysis. Edward Arnold Publishers, London.

JANUÁRIO, M., VISWANADHAN, Y. \& SENNA, R.C. 1992. Radiação solar total dentro de floresta tropical úmida de terra firme (Tucuruí, Pará). Acta Amazonica 22:335-340.

JOHANSEN, P.A. 1940. Plant microtechnique. McGraw Hill Book Company, New York.

KITAJIMA, K. 1996. Ecophysiology of tropical tree seedlings. In Tropical forest plant ecophysiology (S.S. Mulkey, R.L. Chazdon \& A.F. Smith, eds.). Chapman \& Hall, New York, p.559-596.

KITAO, M., LEI, T.T., KOIKE, T., TOBITA, H. \& MARUYAMA, Y. 2000. Susceptibility to photoinhibition of three deciduous broadleaf tree species with different successional traits raised under various light regimes. Plant, Cell and Environment 23:81-89.

KLEIN, R.M. 1980. Ecologia da flora e vegetação do Vale do Itajaí. Sellowia 32:165-389.

LEE, D.W, OBERBAUER, S.F., KRISHNAPILAY, B., MANSOR, M., MOHAMED, H. \& YAP, S.K. 1997. Effects of irradiance and spectral quality on seedlings development of two Southeast Asian Hopea species. Oecologia 110:1-9.

MATTOS, M.D.L. de \& MATTOS, C.C.L.V. 1976. Palmito juçara - Euterpe edulis Mart. (Palmae) - uma espécie a plantar, manejar e proteger. Brasil Florestal 7:9-20.

OBERBAUER, S.F. \& STRAIN, B.R. 1985. Effects of light regime on the growth and physiology of Pentaclethra macroloba (Mimosaceae) in Costa Rica. Journal of Tropical Ecology 1:303-320.

OSBORNE, B.A., CLABBY, G.T., HORSLEY, D. \& NOLAN, P.F. 1994. Is acclimation required for success in high light environments? A case study using Mycelis muralis (L.) Dumort (Asteraceae). New Phytologist 127:63-375.

OSUNKOYA, O.O. \& ASH, J.E. 1991. Acclimation to a change in light regime in seedlings of six Australian rainforest tree species. Australian Journal of Botany 39:591-605.

OSUNKOYA, O.O., ASH, J.E., HOPKINS, M.S. \& GRAHAN, A. 1994. Influence of seed size and seedling ecological attributes on shade-tolerance of rain-forest tree species in northen Queensland. Journal of Ecology 82:149-163.

POPMA, J. \& BONGERS, F. 1991. Acclimation of seedlings of three Mexican tropical rain forest tree species to a change in light availability. Journal of Tropical Ecology 7:85-97.
POORTER, L. 1999. Growth response of 15 rain-forest tree species to a ligth gradient: the relative importance of morphological and physiological traits. Functional Ecology 13:396-410.

REICH, P.B., TJOELKER, M.G., WALTERS, M.B., VANDERKLEIN, D.W. \& BUSCHENA, C. 1998. Close association of RGR, leaf and root morphology, seed mass and shade tolerance in seedlings of nine boreal tree species grown in high and low light. Functional Ecology 12:327-338.

REIS, A., KAGEYAMA, P.Y., REIS, M.S. dos \& FANTINI, A.C. 1996. Demografia de Euterpe edulis Martius (Arecaceae) em uma floresta ombrófila densa montana, em Blumenau (SC). Sellowia 45-48:5-37.

REIS, M.S. dos, NODARI, R.O., GUERRA, M.P. \& REIS, A. 1987. Desenvolvimento do palmiteiro: I. Caracterização até os 18 meses sob diferentes níveis de sombreamento. In: Anais do $1^{\circ}$ Encontro Nacional de Pesquisadores em Palmito, EMBRAPA-CNPF, Curitiba, p.14-145.

REIS, A., REIS, M.S. dos \& FANTINI, A.C. 1991. O palmiteiro como um modelo de manejo em rendimento sustentado. Higiene Alimentar 5:27-31.

SCALON, S.P.Q. \& ALVARENGA, A.A. 1993. Efeito do sombreamento sobre a formação de mudas de pau-pereira (Playcyamus regnellii Benth.). Revista Árvore 17:65-270.

SNEDECOR, G.W. 1962. Statistical methods. The Iowa University Press, Iowa.

SONOIKE, K. 1996. Photoinhibition of photosystem I: Its physiological significance in the chilling sensitivity of plants. Plant Cell Physiology 37:239-247.

STRAUS-DEBENEDETTI, S. \& BAZZAZ, F.A. 1996. Photosynthetic characteristics of tropical trees along successional gradients. In Tropical forest plant ecophysiology. (S.S. Mulkey, R.L. Chazdon \& A.P. Smith, eds.). Chapman Hall, New York, p.162-186.

THOMPSON, W.A., HUANG, L.K. \& KRIEDEMANN, P.E. 1992. Photosynthetic response to light and nutrients in sun-tolerant and shade tolerant rainforest trees. II. Leaf gas exchange and component processes of photosynthesis. Australian Journal of Plant Physiology 19:19-42.

TURNBULL, M.H. 1991. The effect of light quantity and quality during development on the photosynthetic characteristics of six Australian rainforest tree species. Oecologia 87:110-117.

VALLADARES, F., ALLE, M.T. \& PEARCY, R. 1997. Photosynthetic responses to dynamic light under field conditions in six tropical rainforest shrubs occuring along a light gradient. Oecologia 111:505-514.

VALLADARES, F., WRIGHT, S.J., LASSO, E., KITAJIMA, K. \& PEARCY, R.W. 2000. Plastic phenotypic response to light of 16 congeneric shrubs from a Panamanian rainforest. Ecology 81:1925-1936.

YAMAZOE, G. 1973. Observações preliminares sobre a cultura de Euterpe edulis Mart. Boletim Técnico do Instituto Florestal 6:17-22. 